\title{
Teleducação em fissura labiopalatina: elaboração de website
}

\author{
Tele-education about cleft lip and palate: development of an \\ educational website about cleft lip and palate
}

\author{
Melissa Picinato-Pirola ${ }^{10}$, Marilia Gabriela Gonçalves Ribeiro ${ }^{1}$ (D), Raíssa Gomes Magalhães ${ }^{1}$ (D), \\ Thiago Pestillo Seles ${ }^{2}$ (D), Camila de Castro Corrêa ${ }^{1,3}$ (1)
}

\begin{abstract}
RESUMO
Objetivo: elaborar um website de cunho educacional sobre fissura labiopalatina para profissionais e estudantes da área da saúde. Métodos: trata-se de um estudo qualitativo, exploratório, estruturado a partir da proposta de design instrucional, composta por quatro fases: análise e planejamento (busca nas bases científicas), modelagem (estruturação com o conteúdo, ilustrações e questionário), avaliação (por especialistas que atuam na área) e implementação (disponibilização do website). Resultados: na fase de análise e planejamento foram encontrados 408 artigos para estruturar os tópicos do website. Na modelagem, o conteúdo foi dividido em 7 seções, criadas 16 imagens estáticas e um questionário avaliativo. Na fase de avaliação, participaram 10 fonoaudiólogas especialistas que sugeriram a manutenção de 7 seções no website. Todas as avaliações com sugestões de modificações que tiveram índice de concordância abaixo de $90 \%$ foram atendidas, tanto no conteúdo, como no questionário. Após, o website foi reformulado, assim como o questionário, para futura avaliação dos usuários. O website está disponibilizado em www.fissuralabiopalatina.unb.br. Conclusão: por meio da sistemática do design instrucional, o website sobre fissuras labiopalatina foi constituído para a orientação de estudantes, profissionais da área da saúde e população em geral.
\end{abstract}

Palavras-chave: Fenda labial; Fenda palatina; Educação em saúde; Telemedicina; Fonoaudiologia

\begin{abstract}
Purpose: to create an educational website about cleft lip and palate for healthcare professionals and students. Methods: a qualitative and exploratory study structured from a design proposal consisting of the following four phases: analysis and planning (review of scientific data), modeling (structuring with content and illustrations), evaluation (by experts working in the area) and final implementation (website availability). Results: in the analysis and planning phase, 408 articles were used to structure the website's topics. In the modeling phase, the content was divided into 7 sections, 16 static images and an evaluative questionnaire were created. In the evaluation phase 10 specialized speech-language pathologists participated and suggested maintaining 7 sections on the website. All evaluations with suggestions for modifications that had an agreement index below $90 \%$ were met, both in content and in the questionnaire. Afterward, the website and questionnaire were updated for future user evaluation. The website is available at www. fissuralabiopalatina.unb.br. Conclusion: we concluded that through systematic instructional design the website about cleft lip and palate was created for the orientating students, healthcare professionals and the public alike.
\end{abstract}

Keywords: Cleft lip; Cleft palate; Health education; Telemedicine; Speech, language and hearing sciences

\footnotetext{
Trabalho realizado na Faculdade de Ceilândia, Universidade de Brasília - Brasília (DF), Brasil.

${ }^{1}$ Faculdade de Ceilândia, Universidade de Brasília - Brasília (DF), Brasil.

${ }^{2}$ Faculdade de Arquitetura, Artes e Comunicação, Universidade Estadual Paulista - UNESP - São Paulo (SP), Brasil.

${ }^{3}$ Centro Universitário Planalto do Distrito Federal - UNIPLAN - Brasília (DF), Brasil.

Conflito de interesses: Não.

Contribuição dos autores: MPP foi responsável pela estruturação do trabalho, delineamento do estudo, coleta, tabulação, análise e interpretação dos dados, redação e revisão do artigo e consentimento da versão final para publicação; MGGR foi responsável pela estruturação do trabalho, coleta, tabulação, análise e interpretação dos dados, redação, revisão do artigo e consentimento da versão final para publicação; RGM foi responsável pela estruturação do website, análise e interpretação dos dados, redação, revisão do artigo e consentimento da versão final para publicação; TPS foi responsável pela estruturação do website, análise e interpretação dos dados, redação, revisão do artigo e consentimento da versão final para publicação; CCC foi responsável pela estruturação do website, análise e interpretação dos dados, redação, revisão do artigo e consentimento da versão final para publicação.
}

Financiamento: Fundação de Apoio à Pesquisa do Distrito Federal (FAPDF) - fomento para a execução da pesquisa (processo: 0193.001520/2017).

Autor correspondente: Melissa Picinato-Pirola. E-mail: melissapicinato@unb.br

Recebido: Outubro 13, 2020; Aceito: Janeiro 27, 2021 


\section{INTRODUÇÃO}

A fissura labiopalatina (FLP) é uma das malformações mais comuns que ocorre no período embrionário até a $12^{\mathrm{a}}$ semana gestacional e pode causar alterações nas funções de sucção, audição e fala ${ }^{(1,2)}$. Uma vez que os profissionais de saúde lidam diretamente com os pacientes com fissura e seus responsáveis, é fundamental que tenham o conhecimento sobre FLP para orientações e estabelecimento de conduta, além da importância da disponibilidade de informações para a população em geral $^{(3-5)}$, visto que a ausência de orientações pode influenciar de maneira negativa o processo terapêutico dos indivíduos com $\operatorname{FLP}^{(6)}$.

A promoção de conhecimento pode ser feita por meio da Telessaúde, especificamente pela Teleducação, que permite transmitir informações de tecnologias de informação e comunicação (TICs), viabilizando maior alcance, menores custos e maior motivação da população ${ }^{(7)}$. No que se refere à Fonoaudiologia, as publicações ainda são prevalentes nas áreas de audiologia e linguagem, caracterizando-se em trabalhos recentes ${ }^{(8)}$.

Dentre as possibilidades da Teleducação, estão os websites, representados por páginas virtuais com alta flexibilidade de recursos (imagens, vídeos e textos), que podem atender a inúmeras finalidades ${ }^{(9)}$. Em contrapartida, a facilidade em desenvolver e disponibilizar websites, pode culminar na problemática de informações em abundância, nem sempre atualizadas, fidedignas e respaldadas no conteúdo científico. Portanto, estudos recentes, inclusive na área da Fonoaudiologia, ressaltaram que, além da estruturação, desenvolvimento e divulgação de informações online, deve ser considerado o aspecto de avaliação dos conteúdos e da usabilidade da ferramenta, para garantir o objetivo de se atingir, efetivamente, a população-alvo ${ }^{(10-12)}$.

Sendo assim, o presente estudo teve o objetivo de desenvolver um ambiente virtual de aprendizagem (AVA), em formato de website, visando à orientação geral sobre FLP para profissionais e estudantes da área da saúde, além de elaborar um questionário sobre o conhecimento dessa temática.

\section{MÉTODOS}

Trata-se de um estudo qualitativo, exploratório, aprovado pelo Comitê de Ética em Pesquisa em Seres Humanos da Universidade de Brasília (UnB), sob o no de parecer 3.159.051.

$\mathrm{O}$ desenvolvimento do website foi respaldado na literatura científica atualizada e na contribuição da avaliação de profissionais especializados e experientes em fissura labiopalatina. O processo foi estruturado a partir da proposta de design instrucional, composta por quatro fases: análise e planejamento, modelagem, implementação e avaliação ${ }^{(13)}$.

\section{$1^{\text {a }}$ Fase - Análise e Planejamento}

Utilizou-se a literatura científica básica do conteúdo de fissura labiopalatina, por meio do acesso às interfaces LILACS, SciELO e PubMed.

As buscas foram respaldadas no seguinte roteiro:

1. Definição

2. Incidência

\section{Etiologia}

4. Tipo de fissura labiopalatina

5. Diagnóstico

6. Cirurgias primárias

7. Profissionais envolvidos no tratamento

8. Higiene oral

9. Vias de alimentação

10. Audição

11. Fala

12. Linguagem

\section{$2^{\mathrm{a}}$ Fase - Modelagem}

Posteriormente ao roteiro elaborado e às buscas efetuadas, $\mathrm{o}$ material para o website foi construído, utilizando-se a ferramenta Microsoft PowerPoint 2010, para a visualização do conteúdo junto com os recursos gráficos.

Foram selecionados vídeos e imagens já existentes e disponíveis na internet, para facilitar a compreensão dos aspectos abordados.

Além da estruturação do website, foi elaborado um questionário específico, baseado no levantamento bibliográfico realizado na $1^{\mathrm{a}}$ fase e nos aspectos elencados para a construção do website, para que fosse analisada, por avaliadores, a pertinência do seu conteúdo.

$3^{\mathrm{a}}$ Fase - Avaliação

\section{Seleção dos avaliadores}

Para escolha dos participantes do processo de avaliação do website de orientação, foram selecionados, como critérios de inclusão, fonoaudiólogos com experiência em FLP e que trabalhassem em instituições diferentes da instituição responsável pelo estudo. Foram excluídos fonoaudiólogos que não completaram todas as etapas do estudo.

Após aceitarem o convite prosseguiu-se com a explicação do objetivo do estudo e envio das orientações. Todos os participantes concordaram com o Termo de Consentimento Livre e Esclarecido, que foi disponibilizado on-line. Nesta fase do estudo, o website ainda não possuía o endereço eletrônico, logo, para ter acesso ao conteúdo da página, foi oferecido em formato de PDF, com um prazo preestabelecido de três dias para que os participantes realizassem a avaliação do website de orientação. Foi necessário estender o prazo para a participação por mais oito dias, devido à dificuldade de adesão.

\section{Protocolo de avaliação do conteúdo do website}

Para a avaliação do conteúdo teórico do website, foi aplicada a medida quantitativa de porcentagem de concordância, para 
mensurar a concordância interobservadores, sendo utilizada a fórmula:

$\%$ concordância $=\frac{\text { Númerode participantes que concordaram }}{\text { Númerototal de participantes }} \times 100$

Foi considerada a taxa de $90 \%$ como índice de concordância interobservadores ${ }^{(14)}$, ou seja, o conteúdo com a concordância de $90 \%$, ou mais, foi considerado aceitável (sem necessidade de modificação).

Para avaliar o website de orientação, foi utilizado um questionário disponibilizado no Google Formulários, no qual se avaliou o conteúdo teórico do website, no que se refere à abrangência e qualidade, na visão dos avaliadores. As opções de avaliação foram: concordar, discordar e/ou fornecer sugestões. Em uma mesma pergunta, era possível selecionar as duas opções de resposta e realizar sugestões, independente da opção assinalada.

Para a adequação do website de orientação foram consideradas todas as respostas dadas pelos fonoaudiólogos avaliadores e as modificações foram feitas de acordo com as suas sugestões.

\section{Protocolo de avaliação do questionário}

Foi elaborado um questionário para a avaliação do conhecimento de estudantes e profissionais da área da saúde sobre fissura labiopalatina, para que, posteriormente, seja possível comparar o conhecimento prévio e posterior à utilização do website estruturado.

A avaliação do questionário foi realizada pelos mesmos avaliadores, sendo que cada questão foi julgada em um formato de respostas fechadas (satisfatória ou insatisfatória) e, em seguida, havia a possibilidade de fazer sugestões para mudanças. Também foi utilizada a medida quantitativa de porcentagem de concordância, considerando $90 \%$ para mensurar a concordância interobservadores ${ }^{(14)}$, conforme descrito no item anterior.

\section{$4^{\text {a }}$ Fase - Implementação}

A elaboração do website teve o objetivo de disseminar informações para pessoas de diferentes lugares do país, ampliando o alcance das informações científicas para a população em geral. O conteúdo devidamente adaptado, exemplificado por ilustrações, foi implementado por meio de uma plataforma gratuita, que permitiu a estruturação para a sua transmissão.

Posteriormente, ponderando-se a necessidade de aperfeiçoar a linguagem visual relacionada ao website e também de caracterizar o rigor científico, obteve-se o auxílio de um designer, para que realizasse a adaptação e uniformização do conteúdo gráfico (atribuindo o caráter de redesign do website), além do apoio da Diretoria de Sistemas da Informação da instituição, para que se procedesse à transferência para a plataforma oficial da instituição à qual o projeto é vinculado. Foi recebida a orientação de se elaborar um cadastro para eleger o template e, assim, o setor forneceu os devidos suportes técnicos para a execução e disponibilização do website, sendo realizada a estruturação por meio do Joomla (sistema de gerenciamento de conteúdo).

Com o objetivo de estabelecer um design inclusivo, na busca de promover uma abordagem que alcançasse o maior número de pessoas, elaboraram-se as ilustrações com foco em auxiliar a informação da página, promover maior eficiência com a comunicação e facilitar a assimilação e a recordação do conteúdo. Para isso, consideraram-se os seguintes parâmetros ${ }^{(15-17)}$, levantados na elaboração das imagens:

Fatores técnicos:

- Ressaltou-se a utilização de traços simples para facilitar a comunicação, que deveria ser compreensível e apropriada ao usuário final;

- Aplicou-se a identidade do projeto, gerando identificação com a universidade e seu website;

- As cores foram utilizadas para vincular a escrita e as imagens aos traços e às flechas;

- Buscou-se evitar variações em seu acabamento, mantendo uma padronização e especificidade no estilo aplicado;

- As imagens foram utilizadas na qualidade adequada, evitando-se a baixa qualidade e imagens com tamanhos que excedessem a quantidade suportada pelo website, $\mathrm{o}$ que dificultaria o carregamento da página;

- Buscou-se deixar as informações escritas próximas às figuras.

Fatores simbólicos:

- Elaboraram-se personagens que se repetem ao longo do projeto, buscando gerar maior empatia;

- Aplicaram-se representações familiares para gerar identificação e naturalidade nas representações;

- Para alcançar um maior tempo de permanência no website, foram criadas imagens estáticas contextualizadas e esclarecedoras, além de esteticamente agradáveis, visando estimular o usuário.

\section{RESULTADOS}

\section{$1^{\text {a }}$ Fase - Análise e planejamento}

Foi realizada a busca nas bases científicas. A distribuição dos temas, em quantidade de artigos, está apresentada na Figura 1.

Por meio dessas buscas, foram estruturados os tópicos propostos no roteiro, simplificando a linguagem, e sendo o mais direto possível, com informações pontuais, para que se estabelecesse linguagem e conteúdos atrativos para o público diversificado que se objetivava atingir.

\section{$2^{\text {a }}$ Fase - Modelagem}

O conteúdo foi dividido em 7 seções, da seguinte forma: objetivo do site, definição, causas, tratamentos (cirurgias primárias), curiosidades, tipos de fissura e dúvidas frequentes, sendo as duas últimas divididas em subseções, que englobam fissuras de lábio e palato, fissura submucosa, alimentação, audição, fala e linguagem.

Conforme a estruturação do assunto, somado ao conteúdo, foram criadas, pelo designer, 16 imagens estáticas, buscando 


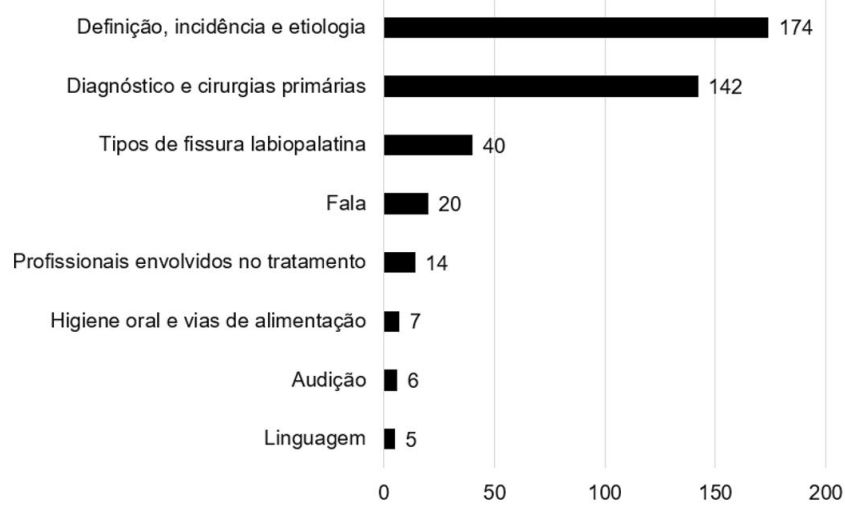

Figura 1. Assuntos localizados nas bases de dados da busca na literatura para a fundamentação teórica do conteúdo sobre fissura labiopalatina

facilitar o entendimento da informação e motivar o usuário a conhecer todo o conteúdo do website.

\section{$3^{\text {a }}$ Fase - Avaliação}

\section{Seleção dos avaliadores}

Ao total, foram convidados 21 fonoaudiólogos com experiência em FLP, por meio de e-mail padrão, porém, 10, do sexo feminino, responderam ao e-mail e completaram todas as fases do estudo. Todas possuíam experiência com fissura por atuarem, ou já terem atuado em centros de referência no atendimento de FLP. A média do tempo de atuação das fonoaudiólogas, especificamente com FLP, era de 18,9 anos, variando entre 8 e 36 anos (Tabela 1).

\section{Protocolo de avaliação do conteúdo do website}

Na avaliação do website, atingiu-se o índice de concordância interobservadores de $90 \%$ no item parto, que não sofreu nenhuma alteração. Os demais itens não atingiram valor de concordância interobservadores de 90\%, porém, apresentaram o valor de concordância de $80 \%$ em relação à aparência do website e a definição da FLP; 72,7\% no item incidência da FLP; 70\% nos itens etiologia e profissionais envolvidos no tratamento; $60 \%$ nos itens tipos de FLP e diagnóstico; 58,3\% no item higiene oral; $50 \%$ nos itens alimentação, audição e fala e 45,5\% no item cirurgias primárias (Quadro 1).

Para as reformulações, levaram-se em consideração as sugestões das avaliadoras e as temáticas que sofreram alterações quanto ao embasamento teórico foram: a classificação dos tipos de FLP, o período de realização das cirurgias primárias, o diagnóstico, a alimentação, a higiene oral, a audição e a fala. As demais temáticas, como aparência do website, definição da FLP, etiologia, incidência e profissionais envolvidos no tratamento não tiveram alterações no conteúdo teórico, apenas alterações em relação à forma como foram catalogadas na problemática (Quadro 1).
Tabela 1. Tempo médio de atuação com fissura labiopalatina dos avaliadores

\begin{tabular}{cc}
\hline Avaliadores & Tempo de atuação com FLP (anos) \\
\hline Avaliador 1 & 26 \\
Avaliador 2 & 36 \\
Avaliador 3 & 13 \\
Avaliador 4 & 8 \\
Avaliador 5 & 30 \\
Avaliador 6 & 14 \\
Avaliador 7 & 16 \\
Avaliador 8 & 10 \\
Avaliador 9 & 18 \\
Avaliador 10 & 18 \\
MÉDIA TOTAL & $\mathbf{1 8 , 9}$ \\
\hline
\end{tabular}

Legenda: FLP = fissura labiopalatina

\section{Protocolo de avaliação do questionário}

$\mathrm{Na}$ análise do questionário, as perguntas referentes à definição da FLP, período gestacional em que ocorre a FLP, tipos de FLP, diagnóstico, cirurgias primárias, alimentação e fala tiveram os seus enunciados e as opções de resposta reformulados. A pergunta referente à etiologia teve o enunciado reformulado e a pergunta sobre as classificações da FLP foi excluída. Foi acrescentada uma pergunta sobre o diagnóstico após o nascimento e uma pergunta sobre a higiene oral. As perguntas sobre o tipo de parto, necessidade da atuação de uma equipe multidisciplinar e relevância do estudo não sofreram alterações (Quadro 2).

Sendo assim, considerando as sugestões das avaliadoras, foi finalizada a elaboração do questionário, resultando em um instrumento com 17 questões (Apêndice 1).

\section{$4^{\text {a }}$ Fase - Implementação}

O website foi desenvolvido e encontra-se disponível no endereço: www.fissuralabiopalatina.unb.br ${ }^{(18)}$

Para exemplificação das etapas supracitadas, foram detalhadas imagens do website antes e após o redesign e o apoio da Diretoria de Sistemas da Informação da instituição de origem (Figura 2).

\section{DISCUSSÃO}

A elaboração do website surgiu da necessidade de fornecer um material com informações gerais e atuais sobre a FLP para os estudantes e profissionais da área da saúde, uma vez que é elevada sua ocorrência e, portanto, provavelmente serão requisitados para essa atuação. $\mathrm{O}$ fornecimento de orientações gerais sobre FLP por meio de um website é considerado relevante, por ser um instrumento de fácil acesso, podendo auxiliar na conduta terapêutica. Por outro lado, é importante que a população em geral tenha acesso a tais informações, pois mesmo após consultas, podem ocorrer falhas na comunicação entre pacientes e profissionais da saúde, gerando dificuldades na compreensão de alguns dos assuntos abordados ${ }^{(15,16)}$.

Reforçando o propósito do presente estudo, em uma investigação com 100 mães de crianças com FLP, 32 mães 
Quadro 1. Resposta das avaliadoras sobre a aparência e o conteúdo teórico do website

\begin{tabular}{|c|c|c|c|}
\hline Itens Avaliados & Concordo (\%) & Discordo (\%) & Adequações Realizadas \\
\hline $\begin{array}{l}\text { Aparência do } \\
\text { Website }\end{array}$ & $8(80 \%)$ & $2(20 \%)$ & $\begin{array}{l}\text { - Acrescentada a logomarca da universidade responsável pelo estudo e departamento que } \\
\text { elaborou. }\end{array}$ \\
\hline $\begin{array}{l}\text { Definição da } \\
\text { FLP }\end{array}$ & $8(80 \%)$ & $2(20 \%)$ & $\begin{array}{l}\text { - Reformulada a forma de apresentação, enfatizando que a FLP é a alteração congênita que } \\
\text { mais afeta a face. }\end{array}$ \\
\hline Etiologia/causas & $7(70 \%)$ & $3(30 \%)$ & $\begin{array}{l}\text { - Reformulado, enfatizando que a FLP não tem uma causa definida, ocorrendo por causas } \\
\text { multifatoriais. }\end{array}$ \\
\hline Tipos de FLP & $6(60 \%)$ & $4(40 \%)$ & $\begin{array}{l}\text { - Acrescentadas legendas às imagens dos tipos de FLP, assim como a descrição de úvula } \\
\text { bífida, diástase muscular e entalhe ósseo no palato duro; } \\
\text { - Excluída uma imagem que dificultava a visualização da fissura submucosa; } \\
\text { - Acrescentada a fissura submucosa oculta. }\end{array}$ \\
\hline $\begin{array}{l}\text { Cirurgias } \\
\text { primárias\# }\end{array}$ & $5(45,5 \%)$ & $6(54,5 \%)$ & $\begin{array}{l}\text { - Modificado o título do tópico de "Correção" para "Tratamentos"; } \\
\text { - Foi retirado o período específico para a realização das cirurgias; } \\
\text { - Destacado que a cirurgia dependerá do protocolo utilizado. }\end{array}$ \\
\hline Incidência\# & $8(72,7 \%)$ & $3(27,3 \%)$ & - Destacado que a incidência apresentada é referente à população brasileira e não mundial. \\
\hline Diagnóstico & $6(60 \%)$ & $4(40 \%)$ & $\begin{array}{l}\text { - Acrescentado que o diagnóstico realizado por meio ultrassonografia será no período pré- } \\
\text { natal; } \\
\text { - Acrescentado o diagnóstico após o nascimento nos variados tipos de FLP. }\end{array}$ \\
\hline $\begin{array}{l}\text { Profissionais } \\
\text { envolvidos no }\end{array}$ & $7(70 \%)$ & $3(30 \%)$ & $\begin{array}{l}\text { - Reformulado para: o tratamento poderá ser realizado por meio de uma equipe } \\
\text { multidisciplinar e/ou interdisciplinar; }\end{array}$ \\
\hline tratamento & & & $\begin{array}{l}\text { - Enfatizada a atuação do fonoaudiólogo, ortodontista e o cirurgião plástico que estarão } \\
\text { atuando com o paciente desde o início do tratamento. }\end{array}$ \\
\hline Parto* & $9(90 \%)$ & $1(10 \%)$ & - Não houve alterações. \\
\hline Alimentação & $5(50 \%)$ & $5(50 \%)$ & $\begin{array}{l}\text { Foi reformulado em relação a: } \\
\text { - Forma de alimentação: dependerá do tipo de fissura; } \\
\text { - Oferta do alimento: será por meio dos utensílios e/ou vias alimentares que forem mais } \\
\text { seguros para a criança; } \\
\text { - Acrescentado que será a equipe multidisciplinar que auxiliará nesse processo. }\end{array}$ \\
\hline Higiene Oral\# & $7(58,3 \%)$ & $5(41,7 \%)$ & $\begin{array}{l}\text { - Acrescentada a higiene nasal; } \\
\text { - Acrescentado vídeo ilustrativo de como realizar a higiene oronasal. }\end{array}$ \\
\hline Audição & $5(50 \%)$ & $5(50 \%)$ & $\begin{array}{l}\text { - Reformulada a forma de apresentação das informações; } \\
\text { - Modificado para a estrutura em forma de tópicos; } \\
\text { - Enfatizado que a alteração auditiva ocorre nas fissuras que acometem o palato; } \\
\text { - Acrescentadas imagens para facilitar a visualização do sistema auditivo. }\end{array}$ \\
\hline Fala & $5(50 \%)$ & $5(50 \%)$ & $\begin{array}{l}\text { - Reformulada a forma de apresentação das informações; } \\
\text { - Modificado para a estrutura em forma de tópicos. }\end{array}$ \\
\hline
\end{tabular}

Medida Quantitativa de Porcentagem de Concordância *Não teve alterações \#Avaliadoras ora responderam concordando, ora discordando no mesmo item

Legenda: FLP = fissura labiopalatina

relataram defasagem na orientação sobre algum aspecto da FLP por parte dos profissionais da área da saúde que atenderam seus filhos, enfatizando a importância da capacitação dos profissionais somada a outros meios de reforços do conhecimento ${ }^{(5)}$.

No que se refere à temática específica da FLP voltada para orientação de profissionais e estudantes, a literatura é escassa, porém, demonstra a importância da conscientização desde a população infantil, para se criar um entorno mais favorável à inclusão, minimizando o preconceito em relação aos indivíduos com $\mathrm{FLP}^{(12)}$. Já sobre orientações voltadas aos profissionais da área da saúde, houve o desenvolvimento de um blog, que utilizou o questionário Emory como ferramenta para mensurar a sua qualidade ${ }^{(3)}$. O que diferenciou o presente estudo foi a preocupação com a elaboração de um instrumento específico para posterior avaliação, que possibilitasse a mensuração do conhecimento sobre FLP. Assim, futuramente, poderá se comparar o conhecimento prévio e após a utilização do website estruturado.

Além disso, uma vez que se trata de um assunto específico e teórico, com informações sobre FLP, julgou-se importante a avaliação, comprovando sua qualidade por meio da análise e concordância ${ }^{(14)}$ de especialistas na área, garantindo que os tópicos apresentados puderam transmitir a mensagem estruturada previamente de forma eficaz e permitindo que o instrumento seja amplamente utilizado em futuros estudos.

Obteve-se a atuação efetiva de dez fonoaudiólogas como avaliadoras, atribuindo-se menor casuística pela criteriosa admissão para a participação no presente estudo. Sendo assim, todas as avaliadoras apresentaram experiência prática no atendimento de pacientes com FLP, com tempo médio de atuação fonoaudiológica com FLP de 18,9 anos, trabalhando em instituição distinta, sem conflito de interesse, a fim de não influenciar positivamente ou negativamente na avaliação do website e do questionário.

Outro exemplo de construção de material para orientar os cuidadores de pacientes com FLP sobre a função velofaríngea, fala e cirurgia para correção da FLP consistiu em orientações elaboradas em materiais multimídias no programa PowerPoint. Após a comparação dos conhecimentos dos cuidadores no momento pré e pós-aplicação do material multimídia, observou- 
Quadro 2. Avaliação das questões para elaboração do questionário pré e pós-acesso ao website, para mensurar o impacto das informações de fissuras labiopalatinas

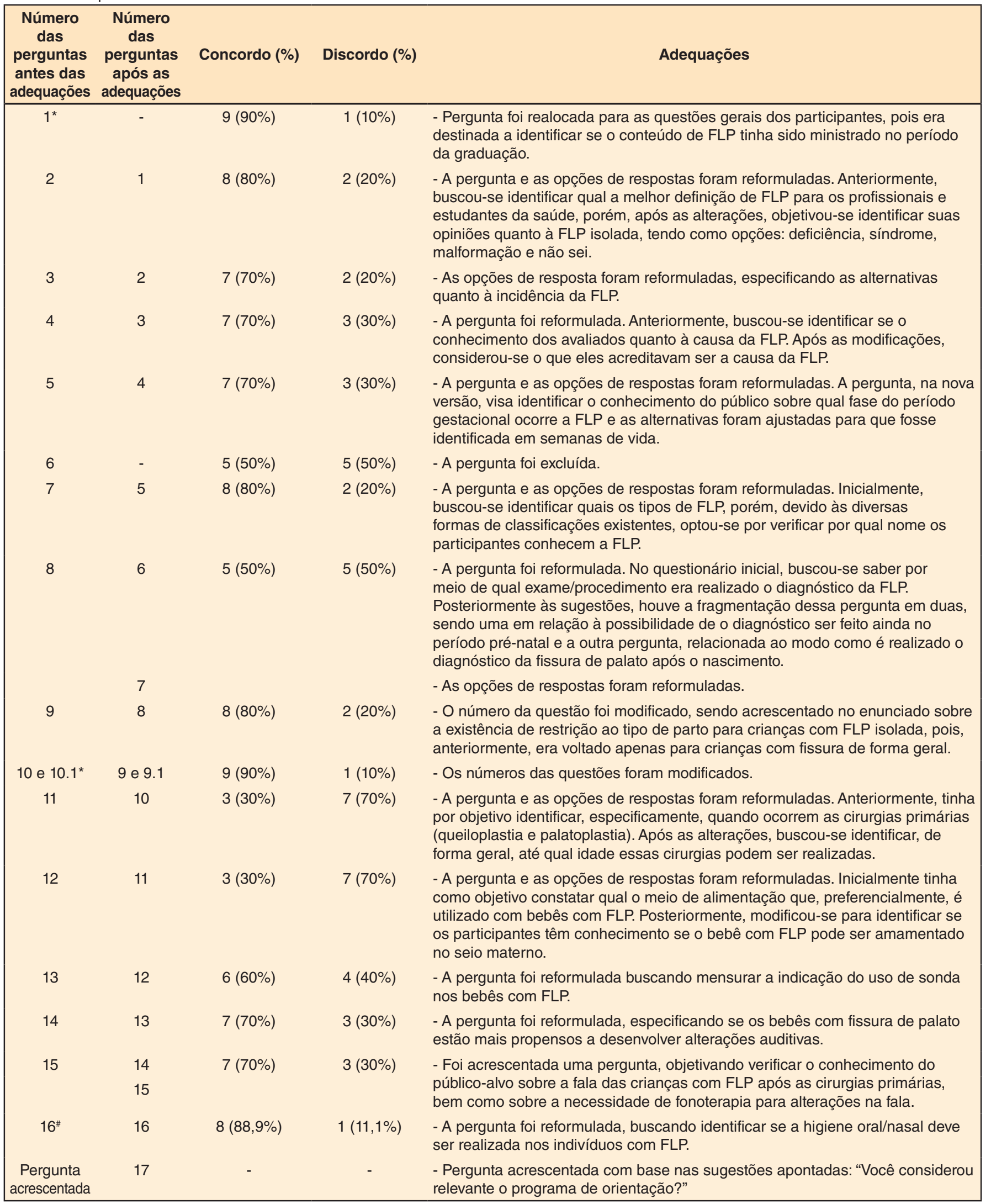

*Não teve alterações \#Avaliadora não respondeu

Legenda: FLP = fissura labiopalatina 


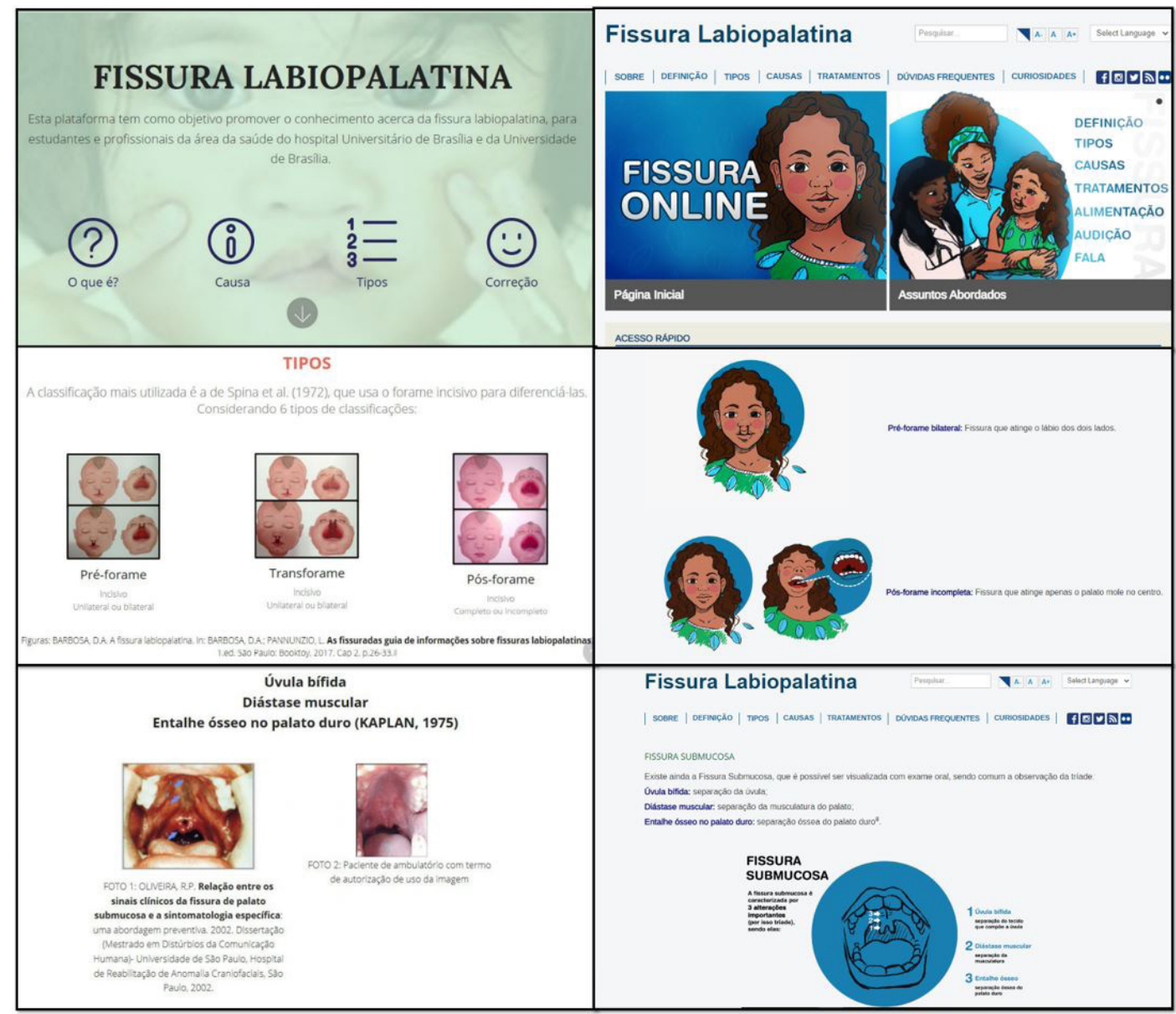

Figura 2. Prints ilustrativos do primeiro formato do website, à esquerda, e exemplos de como o website ficou após o redesign e alocação na página da instituição à qual se vincula este projeto

se que, de $61 \%$ de acertos no momento inicial, o segundo momento obteve $86 \%$ de acertos em média ${ }^{(17)}$, demonstrando a possibilidade de contribuir com o conhecimento da população em geral por meio de materiais multimídia.

Em relação às sugestões feitas pelas avaliadoras, os conteúdos teóricos do website que sofreram alterações foram: tipos de FLP (60\% de concordância entre as avaliadoras), formas de diagnóstico antes e após o nascimento (60\% de concordância), período de realização das cirurgias primárias $(45,5 \%$ de concordância), alimentação (50\% de concordância), audição ( $50 \%$ de concordância), higiene oral (58,3\% de concordância) e fala (50\% de concordância) (Quadro 1). Os demais itens do website tiveram sugestões de modificações em relação à forma de apresentação, com exceção apenas do item parto, que não teve nenhuma alteração. Apesar das modificações já efetuadas, existe um planejamento para se realizar outras avaliações, bem como outras modificações pertinentes, além de constantes atualizações, partindo do princípio de que o conhecimento é dinâmico e a necessidade do acesso à informação também é variável ao longo do tempo e das gerações.

Como exemplo das avaliações e sugestões sobre as formas de diagnóstico das fissuras de lábio, palato ou lábio e palato, pode ser realizado no período pré-natal, por meio da ultrassonografia bidimensional ou tridimensional. Já em alguns casos, o diagnóstico pré-natal pode não ocorrer, devido ao posicionamento do bebê $\hat{}^{(19,20)}$. Para esses casos, o diagnóstico será realizado após o nascimento, por meio da avaliação clínica associada a avaliação instrumental ${ }^{(21,22)}$. Assim, sobre esse aspecto, $60 \%$ das avaliadoras concordaram com o que foi apresentado no website, que descrevia o diagnóstico pré-natal. Porém, recomendaram acrescentar o diagnóstico após o nascimento, sendo que, nas sugestões, duas avaliadoras $(20 \%)$ consideraram a avaliação clínica após o nascimento a forma de diagnóstico mais precisa.

Em relação à avaliação do questionário, apenas a questão referente ao tratamento do indivíduo com fissura labiopalatina dentro de uma equipe multidisciplinar não foi modificada, pois se obteve $90 \%$ de concordância entre as avaliadoras. As demais questões foram modificadas de acordo com as sugestões apresentadas (Quadro 2). Os índices mais baixos de concordância foram nas questões referentes às cirurgias primárias da FLP e alimentação, sendo que ambas tiveram $30 \%$ de concordância.

Referente às cirurgias primárias, no questionário anterior às modificações constavam opções dos períodos exatos para a realização das cirurgias de queiloplastia e palatoplastia. Após as sugestões apontadas, buscou-se identificar, de forma geral, até qual idade essas cirurgias podem ser realizadas. A alteração nessa questão foi relevante, pois o período de realização das cirurgias primárias dependerá do protocolo adotado por cada centro especializado, mas, geralmente, acontece primeiro ano de vida ${ }^{(1,23)}$.

Quanto à alimentação, o questionário apresentado às avaliadoras tinha como objetivo constatar qual o meio de alimentação é utilizado, preferencialmente, em bebês com FLP. Após as sugestões, o objetivo da questão foi identificar se 
os participantes têm conhecimento se o bebê com FLP pode ser amamentado no seio materno. Os bebês com FLP podem apresentar dificuldades na amamentação em seio materno, devido à presença de fraca pressão intraoral nos casos de fissura de palato $^{(1,5)}$, porém, é importante salientar que a amamentação em seio materno em muitos casos é possível, mesmo na presença de fissura de palato, e deve ser priorizada.

Com base nisso, evidencia-se a necessidade de mais estudos relacionados ao conhecimento dos profissionais e estudantes da área da saúde, assim como a importância da disseminação do conhecimento por meio de materiais informativos sobre a temática, para orientações aos responsáveis por crianças com FLP.

\section{CONCLUSÃO}

Por meio da sistemática do design instrucional, o website de orientação foi elaborado para os estudantes e profissionais da área da saúde, sendo aprimorado a partir das sugestões realizadas por fonoaudiólogas com experiência em FLP. Encontra-se disponível no endereço www.fissuralabiopalatina.unb.br

\section{REFERÊNCIAS}

1. Freitas JAS, Neves LT, Almeida LPF, Garib DG, Trindade-Suedam IK, Yaedú RYF, et al. Rehabilitative treatment of cleft lip and palate: experience of the Hospital for Rehabilitation of Craniofacial Anomalies/USP (HRAC/USP) Part 1: overall aspects. J Appl Oral Sci. 2012;20(1):9-15. http://dx.doi.org/10.1590/S1678-77572012000100003. PMid:22437671.

2. Genaro KF, Yamashita RP, Trindade IEK. Avaliação clínica e instrumental da fala na fissura labiopalatina. In: Fernandes FDM, Mendes BCA, Navas ALGP. Tratado de fonoaudiologia. São Paulo: Editora Roca; 2010. Cap. 53, p. 488-503.

3. Maximino LP, Zambonato TCF, Picolini-Pereira MM, Castro Corrêa C, Feniman MR, Blasca WQ. Development and evaluation of a blog about cleft lip and cleft palate and hearing. Int Arch Otorhinolaryngol. 2018;22(1):60-7. http://dx.doi.org/10.1055/s-0037-1603494. PMid:29371900.

4. Vanz AP, Ribeiro NRR. Escutando as mães de portadores de fissuras orais. Rev Esc Enferm USP. 2011;45(3):596-602. http://dx.doi. org/10.1590/S0080-62342011000300007. PMid:21710063.

5. Silva LS, Leandro TP, Macedo FRM, Silva RF, De Souza ALT, Souza BDOP, et al. Orientações recebidas pelas mães de crianças com fissura labiopalatina. Arq Ciênc Saúde. 2015;22(2):88-93. http://dx.doi. org/10.17696/2318-3691.22.2.2015.149.

6. Amaral MIR, Martins JE, Santos MFC. A study on the hearing of children with non-syndromic cleft palate/lip. Braz. J. Otorhinolaryngol. (Impr.). 2010;76(2):164-71. http://dx.doi.org/10.1590/S180886942010000200004 .

7. Wen CL. Telemedicina e Telessaúde: um panorama no Brasil. Inform Pública. [Internet]. 2008 [citado em 2020 Jul 13];10(2):7-15. Disponível em: http://www.ip.pbh.gov.br/ANO10_N2_PDF/telemedicina_telesaude. pdf

8. Molini-Avejonas DR, Rondon-Melo S, de La Higuera Amato CA, Samelli AG. A systematic review of the use of telehealth in speech, language and hearing sciences. J Telemed Telecare. 2015;21(7):36776. http://dx.doi.org/10.1177/1357633X15583215. PMid:26026181.
9. Significados. Significado de website [Internet]. 2019 [citado em 2019 Abr 11]. Disponível em: https://www.significados.com.br/website

10. Pulga MJ, Spinardi-Panes AC, Lopes-Herrera SA, Maximino LP. Evaluating a speech-language pathology technology. Telemed J E Health. 2014;20(3):269-71. http://dx.doi.org/10.1089/tmj.2013.0052. PMid:24404815.

11. Oliveira LF, Corrêa CD, Vieira MM, Blasca WQ, Brasolotto AG. Intervenção fonoaudiológica por meio da teleducação sobre a muda vocal e hábitos vocais. Audiol Commun Res. 2018;23:e1899. http:// dx.doi.org/10.1590/2317-6431-2017-1899.

12. Corrêa CC, Freire T, Zabeu JS, Martins A, Ferreira R, Francisconi PA, et al. Teleducation about Cleft Lip and Palate: an interdisciplinary approach in the promotion of health. Int Arch Otorhinolaryngol. 2015;19(2):106-11. http://dx.doi.org/10.1055/s-0034-1544114. PMid:25992163.

13. Filantro A, Piconez SCB. Design instrucional contextualizado: planejamento, elaboração e avaliação de materiais didáticos para Educação a Distância [Internet]. São Paulo: ABED; 2004 [citado em 2011 Abr 19]. Disponível em: http://www.abed.org.br/congresso2004/ por/pdf/049-TC-B2.pdf

14. Alexandre NM, Coluci MZ. Validade de conteúdo nos processos de construção e adaptação de instrumentos de medidas. Cien Saude Colet. 2011;16(7):3061-8. http://dx.doi.org/10.1590/S1413-81232011000800006. PMid:21808894.

15. Iervolino SMS. Elaboração de um guia informativo para pais de crianças candidatas a cirurgia de Implante Coclear. São Paulo: Faculdade de Ciências Médicas, Santa Casa de São Paulo; 2016.

16. Serrasqueiro VB. Materiais educacionais voltados às crianças com transtornos de Aprendizagem: diretrizes sob a ótica do design gráfico inclusivo [dissertação]. Bauru: Universidade Estadual Paulista. Faculdade de Arquitetura, Artes e Comunicação; 2018.

17. Wizowski L, Harper T, Hutchings T. Writing health information for patients and families - A guide to developing educational materials that promote health literacy. 4th ed. Ontário, Canadá: Hamilton Health Sciences; 2014.

18. UNB: Universidade de Brasília. Fissura Labiopalatina [Internet]. Brasília: UNB; 2020 [citado em 2020 Abr 20]. Disponível em: www. fissuralabiopalatina.unb.br

19. Linn AJ, van Dijk L, Smit EG, Jansen J, van Weert JC. May you never forget what is worth remembering: the relation between recall of medical information and medication adherence in patients with inflammatory bowel disease. J Crohns Colitis. 2013;7(11):e543-50. http://dx.doi.org/10.1016/j.crohns.2013.04.001. PMid:23660489.

20. Araújo E Jr, Guimarães HA Fo, Pires CR, Zanforlin SM Fo, Santana RM, Moron AF. Fendas fetais labiais e palatinas detectadas pela ultra-sonografia tridimensional. Revista Imagem. 2005;27(4):263-8.

21. Demathé T, Cunha L. Compreensão, pelos acompanhantes, do conteúdo da receita médica nos atendimentos pediátricos em postos de saúde. ACM arq. catarin. Med. 2008;37(2):51-8.

22. Di Ninno CQ, Gonçalves KC, Braga MS, Miranda IC. Prevalência de fissura de palato submucosa associada à fissura labial. Rev Soc Bras Fonoaudiol. 2011 Set;16(3):304-9. http://dx.doi.org/10.1590/ S1516-80342011000300011.

23. Costa TL, Souza OMV, Carneiro HA, Chiquito C No, PegoraroKrook MI, Dutka JDCR. Material multimídia para orientação dos cuidadores de bebês com fissura labiopalatina sobre velofaringe e palatoplastia primária. CoDAS. 2016 Fev;28(1):10-6. http://dx.doi. org/10.1590/2317-1782/20162014126. PMid:27074183. 
Apêndice 1. Questionário para avaliação do conhecimento de estudantes e profissionais de saúde sobre a fissura labiopalatina após as sugestões das avaliadoras

1. Na sua opinião, o que é a fissura labiopalatina isolada:
a. ( ) Deficiência
b. ( ) Síndrome
c. ( ) Malformação
d. ( ) Não sei

2. Você considera que a incidência da fissura labiopalatina é:
a. ( ) Rara (1:650.000 nascidos vivos)
b. ( ) Comum (1:650 nascidos vivos)
c. ( ) Não sei

3. A causa da fissura labiopalatina é conhecida?

a. ( ) sim

3.1 Cite o que você acredita ser a causa da fissura labiopalatina.

4. A fissura labiopalatina ocorre em qual fase do período gestacional?
a. ( ) Até 12 semanas
b. ( ) De 12 semanas a 21 semanas
c. ( ) De 26 a 30 semanas
d. ( ) a partir de 34 semanas
e. ( ) Não sei

5. Por qual nome você conhece a fissura labiopalatina:
a. ( ) Fissura labiopalatina
b. ( ) Lábio leporino
c. ( ) Goela de lobo
d. ( ) Não sei
e. ( ) Outro

6. O diagnóstico pode ser realizado no pré-natal?
a. ( ) $\operatorname{Sim}$
b. ( ) Não
c. ( ) Não sei

7.Qual a melhor forma de diagnosticar a fissura de palato após o nascimento?

b. ( ) Ultrassonografia Bidimensional

c. ( ) Ultrassonografia Tridimensional

d. ( ) Radiografia

e. ( ) Cefalometria

f. ( ) Ressonância magnética

g. ( ) Tomografia

h. ( ) avaliação clínica/intraoral

i. ( ) Outro

j. ( ) Não sei

8. Existe alguma restrição quanto ao tipo de parto para crianças com fissura labiopalatina isolada?
a. ( ) $\operatorname{Sim}$
b. ( ) Não
c. ( ) Não sei

9. Você acredita que o tratamento do indivíduo com fissura labiopalatina depende de uma equipe multiprofissional?
a. ( ) $\operatorname{Sim}$
b. ( ) Não
c. ( ) Não sei

9.1 Quais profissionais você acredita que estão envolvidos no tratamento da fissura? 
10. Para a correção das fissuras labiopalatinas são realizados procedimentos cirúrgicos, denominadas cirurgias primárias. Com qual idade que geralmente ocorrem:

a. ( ) Nos primeiros dias de vida

b. ( ) Até 6 meses

c. ( ) Até o primeiro ano de vida

d. ( ) Não sei

11. O bebê com fissura de lábio pode ser amamentado no seio materno:
a. ( ) Sim
b. ( ) Não
c. ( ) Não sei

12. É indicado o uso de sonda ao nascimento com os bebês que apresentam fissura labiopalatina sem outros comprometimentos:
a. ( ) $\operatorname{Sim}$
b. ( ) Não
c. ( ) Não sei

13. Os indivíduos com fissura de palato estão mais propensos a desenvolverem alterações auditivas?
a. ( ) $\operatorname{Sim}$
b. ( ) Não
c. ( ) Não sei

14. Você acha que a fala da criança com fissura de lábio pode estar alterada após a cirurgia?
a. ( ) $\operatorname{Sim}$
b. ( ) Não

15. Todas as crianças com fissura labiopalatina necessitam de fonoterapia para a fala?
a. ( ) $\operatorname{Sim}$
b. ( ) Não

16. A higiene oral/nasal deve ser realizada nas crianças com fissura labiopalatina?
a. ( ) $\operatorname{Sim}$
b. ( ) Não

17. Você considerou relevante o programa de orientação? (responder apenas após o programa de orientação) a. ( ) Sim b. ( ) Não.

Sugestões/críticas/elogios para o programa de orientação: 